Delft University of Technology

\title{
Structural health monitoring of adhesively-bonded hybrid joints by acoustic emission
}

Saeedifar, Milad; Saleh, Mohamed Nasr; De Freitas, Sofia Teixeira; Zarouchas, Dimitrios

DOI

10.12783/shm2019/32265

Publication date

2019

Document Version

Final published version

Published in

Structural Health Monitoring 2019

\section{Citation (APA)}

Saeedifar, M., Saleh, M. N., De Freitas, S. T., \& Zarouchas, D. (2019). Structural health monitoring of adhesively-bonded hybrid joints by acoustic emission. In F-K. Chang, A. Guemes, \& F. Kopsaftopoulos (Eds.), Structural Health Monitoring 2019: Enabling Intelligent Life-Cycle Health Management for Industry Internet of Things (IIOT) - Proceedings of the 12th International Workshop on Structural Health Monitoring (Vol. 1, pp. 1437-1444). (Structural Health Monitoring 2019: Enabling Intelligent Life-Cycle Health Management for Industry Internet of Things (IIOT) - Proceedings of the 12th International Workshop on Structural Health Monitoring; Vol. 1). DEStech Publications Inc.. https://doi.org/10.12783/shm2019/32265 Important note

To cite this publication, please use the final published version (if applicable).

Please check the document version above.

\section{Copyright}

Other than for strictly personal use, it is not permitted to download, forward or distribute the text or part of it, without the consent of the author(s) and/or copyright holder(s), unless the work is under an open content license such as Creative Commons.

\section{Takedown policy}

Please contact us and provide details if you believe this document breaches copyrights.

We will remove access to the work immediately and investigate your claim. 
Green Open Access added to TU Delft Institutional Repository

'You share, we take care!' - Taverne project

https://www.openaccess.nl/en/you-share-we-take-care

Otherwise as indicated in the copyright section: the publisher is the copyright holder of this work and the author uses the Dutch legislation to make this work public. 


\title{
COVER SHEET
}

Title: Structural Health Monitoring of Adhesively-Bonded Hybrid Joints by Acoustic Emission for Proceedings of the $\mathbf{1 2}^{\text {th }}$ International Workshop on Structural Health Monitoring 2019

\author{
Authors: Milad Saeedifar \\ Mohamed Nasr Saleh \\ Sofia Teixeira De Freitas \\ Dimitrios Zarouchas
}




\begin{abstract}
The increasing use of Adhesively-bonded joints in industrial applications resulted in more attention to damage assessment in these joints. The aim of the present study is to characterize the damage in bi-material double-lap adhesively-bonded joints by Acoustic Emission (AE). Two different structural adhesives, representing a ductile (Methacrylate-based) and brittle (epoxy-based) types, were used to bond CFRP skins to a steel core. The fabricated joints were loaded in tension while damage evolution was monitored by AE. Due to the difference in the fracture nature of the adhesives "brittle vs. ductile", different damage mechanisms occurred in the specimens; including adhesive layer failure, steel deformation, adhesive/adherends interfacial debonding and delamination in the CFRP skin. In order to distinguish and classify these damages by $\mathrm{AE}$, the $\mathrm{AE}$ features of each damage mechanism were first obtained by conducting some standard tests on the individual constituent materials. Then, These AE reference patterns were used to train an ensemble decision tree classifier. Finally, the trained model classified the AE signals of the double-lap tests and the images token by camera were also employed to verify AE results. This study demonstrates the potential of $\mathrm{AE}$ technique for damage characterization of the adhesively-bonded bi-material joints.
\end{abstract}

\title{
INTRODUCTION
}

The use of adhesively-bonded joints is preferred over conventional joining techniques such as bolting, riveting and welding. They offer many advantages including: the ability to join dissimilar materials such as steel and fiber reinforced composites, weight savings, improved stress distribution along the bond-line and enhancement of the corrosion and fatigue resistance characteristics [1-2].

The damage mechanisms in these joints include, but not limited to: interfacial failure, adhesive layer failure and interlaminar failure within the adherends [3]. Heshmati et al. [4-5] did extensive experimental and numerical studies to investigate the effect of environmental conditions, like moisture, temperature, de-icing salt solution and cyclic loading, on the durability and the damage mechanisms of

Structural Integrity \& Composites Group, Faculty of Aerospace Engineering, Delft University of Technology, Kluyverweg 3, 2629 HS Delft, The Netherlands. 
adhesively-bonded FRP/steel joints. The results showed that the joint strength is function of the dominant failure mode of the joint which varied under different environmental conditions. Thanks to the successful performance of Non-Destructive Evaluation (NDE) techniques, such as Acoustic Emission (AE), for damage assessment in the engineering structures, they can be good candidates for damage characterization in such joints.

AE technique is successfully used in some studies for damage characterization in adhesively-bonded joints [6-8]. Fotouhi et al. [7] monitored different damage mechanisms in a sandwich structure containing a foam core adhesively-bonded to two GFRP skins by AE. They managed to distinguish and classify four different damage mechanisms in the sandwich specimens by analyzing AE data using wavelet packet transform method. $\mathrm{Xu}$ et al. [8] identified damage modes in adhesivelybonded composite single lap joints by means of $\mathrm{AE}$ and k-Means++ unsupervised clustering methods.

Based on the available literature, there are just a few studies on the damage assessment of adhesively-bonded bi-material joints by AE, and most of them used the unsupervised clustering and signal processing methods to classify damage mechanisms. The performance of these methods is not acceptable when the damage AE signals are not clearly distinguishable. Thus, this paper deals with the damage characterization of a double-lap bi-material joint, bonded with a thick adhesive, by supervised classification of AE signals.

\section{MATERIALS and MANUFACTURING}

The double-lap joint consists of two steel cores separated by Teflon insert and bonded with thick adhesive layers $(8 \mathrm{~mm})$ to CFRP skins as depicted in Figure 1. The steel used in this study is high strength structural shipbuilding steel AH36. The CFRP laminates are produced using vacuum infusion. The lay-up was [glass/0/90/45/-45]s. The first adhesive used was a two-component Methacrylate adhesive from SCIGRIP® SG300 Series. The adhesive tensile modulus is 207-276 MPa with a tensile strength of 12-15 MPa and strain to failure of 40-60\%. The second adhesive was a two-component toughned epoxy adhesive from Gougeon Brothers Inc. PROSET Series. The adhesive tensile modulus is $1.93 \mathrm{GPa}$ with a tensile strength of 37 $\mathrm{MPa}$ and strain to failure of $10.1 \%$.

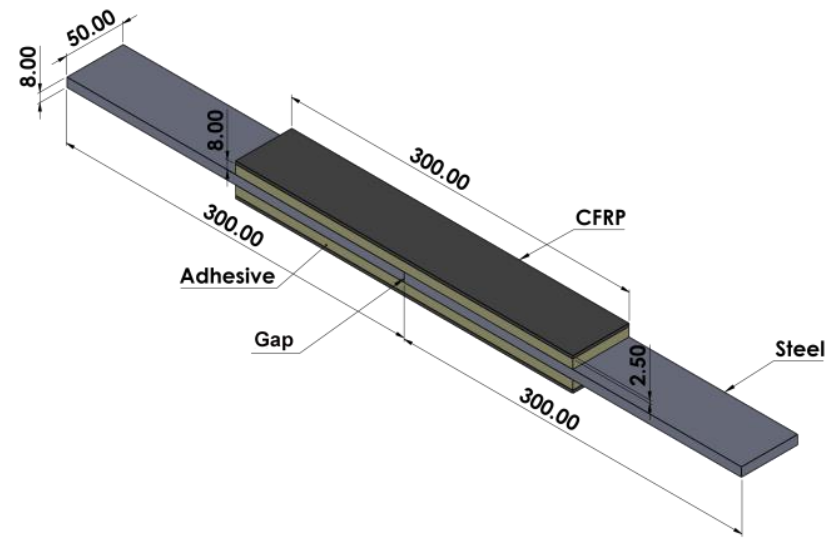

Figure 1. Schematic of the double-lap joint specimen. 


\section{Experimental Procedures}

Tensile testing was conducted in accordance with ASTM D3528 standard [9]. A universal tensile testing machine (Zwick Roell) with $250 \mathrm{kN}$ load cell is used to apply a displacement controlled tension with a rate of $1.27 \mathrm{~mm} / \mathrm{min}$ according to the standard and it records the load and the cross-head displacement. A camera continuously monitors the cross-section of the specimen during the loading process from the opposite side. The AE sensor placed on the specimen surface is used to capture the AE activities of the specimen during the loading process. The AE sensor was a broadband, resonant-type, and single-crystal piezoelectric transducer from Vallen Systeme GmbH, AE1045S-VS900M, with external $34 \mathrm{~dB}$ pre-amplifier and an operating frequency range of $[100-900 \mathrm{kHz}]$. To eliminate the surrounding noises, the threshold was set to $50 \mathrm{~dB}$. The sampling rate was $2 \mathrm{MHz}$. A standard pencil lead break procedure was used to check the connection between the specimen and the AE sensor surface prior to the mechanical test. Three specimens are tested for each adhesive type.

\section{ENSEMBLE BAGGED TREE CLASSIFIER}

The ensemble bagged tree classifier blends several CART decision trees to get a better functionality in comparison with one decision tree. It divides the original training dataset to several subsets. Then a random combination of some subsets is selected to train a specific decision tree and it continues to all the trees be trained. In the prediction phase, the classifier assigns a specific class (label) to a new fed data which the assigned class is one that results in the highest weighted average of the posterior probability computed using the selected trees. For each class $c \in C$ and each tree; $t=1,2, \ldots, T$; the posterior probability $\left(p_{t}(c \mid d)\right)$ of class $c$, given data $d$, using tree $t$ is calculated as:

$$
p_{t}(c \mid d)=\frac{p_{t}(d \mid c) p(c)}{p(d)}
$$

If $S$ is considered as the set of indices of selected trees involved in the class prediction of data $d$, the weighted average of the class posterior probabilities over the selected trees is then calculated as [10]:

$$
p_{\text {Bagged }}(c \mid d)=\frac{\sum_{t=1}^{T} \alpha_{t} p_{t}(c \mid d) I(t \in S)}{\sum_{t=1}^{T} \alpha_{t} I(t \in T)}
$$

where $I(t \in T)$ is 1 if $t$ is in the set $S$, and 0 otherwise, and $\alpha_{t}$ is the weight of tree $t$. Finally, the predicted class $\left(P C_{\text {Bagged }}(c \mid d)\right)$ for data $d$ is the class that yields the largest weighted average [10]:

$$
P C_{\text {Bagged }}(c \mid d)=\underset{c \in C}{\arg \max }\left\{p_{\text {Bagged }}(c \mid d)\right\}
$$

\section{RESULTS and DISCUSSION}

The AE activities of the double-lap specimens under tensile loading were captured by the AE sensor mounted on the surface of the specimens. Figures 2 and 3 
show the load and AE frequency versus the displacement for both types of specimens. The load-displacement response of the Scigrip specimens has a nonlinear behavior from the beginning of the test up to the final failure with a significant plasticity and damage progression leading to a ductile fracture. On the contrary, the loaddisplacement response for the Proset specimens is almost linear up to the final failure, which can be described as a brittle fracture. There is no AE activity for both specimens at the beginning of loading which indicates that there is no damage in the double-lap specimens to start with. The camera images taken from the double-lap specimens also do not show any detectable damage in the specimens in this region. The AE activity of Scigrip specimen starts at the displacement of $2.5 \mathrm{~mm}$ approximately, where a few AE activities were captured with a frequency less than $150 \mathrm{kHz}$. The image of Scigrip specimen at the same instant shows the crack initiation in the adhesive material (see Figure 2(b)). At the displacement of $4 \mathrm{~mm}$, considerable $\mathrm{AE}$ activities start and besides the low-frequency AE signals, some other AE events with a frequency up to $250 \mathrm{kHz}$ are captured. The last AE events' group with a frequency range of [300-400 kHz] initiates at the displacement of $\sim 4.5 \mathrm{~mm}$. All these $\mathrm{AE}$ activities continue to the displacement of $11 \mathrm{~mm}$, where the final fracture occurs.

In the case of the Proset specimens, the first AE activity occurs at the displacement of $0.6 \mathrm{~mm}$ which corresponds to the crack initiation at the adhesive material (see Figure 3(b)). From this point to some moments before the final fracture of the specimen, limited number of $\mathrm{AE}$ events are recorded indicating that there is no considerable damage in the specimen, and that all the applied work on the specimen is stored in the form of strain energy. At the moment of the final fracture, some AE activities with different frequency ranges are captured representing different damage mechanisms activated in the specimen at the same time.

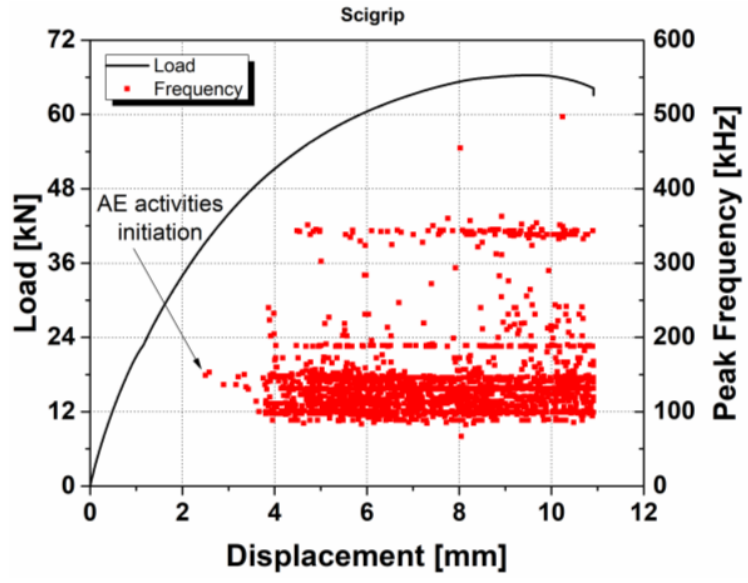

(a)

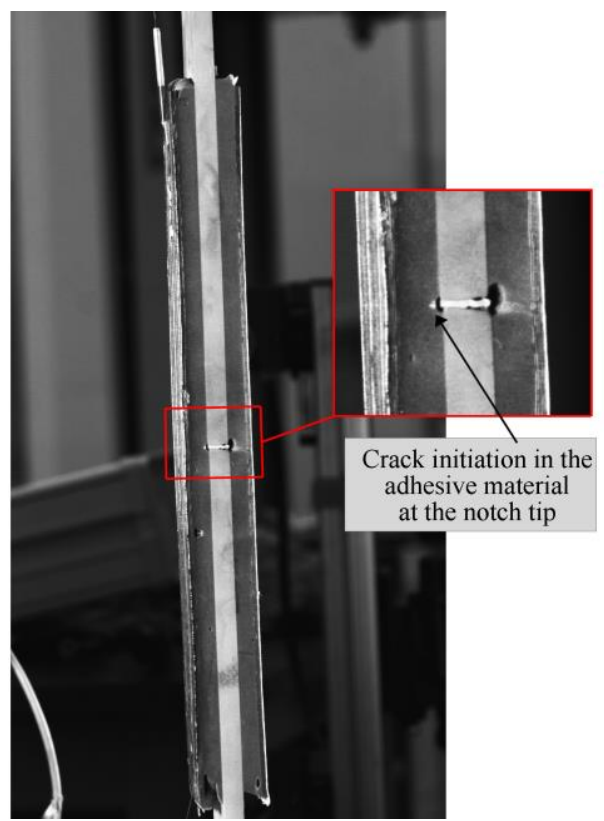

(b)

Figure 2. a) The load and AE frequency versus the displacement, and b) the camera image of Scigrip specimen since AE activities initiate. 


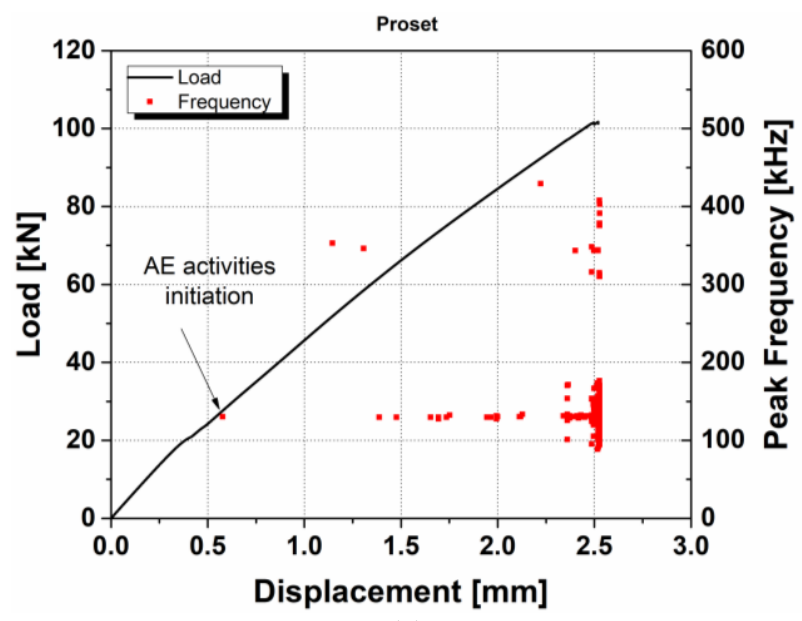

(a)

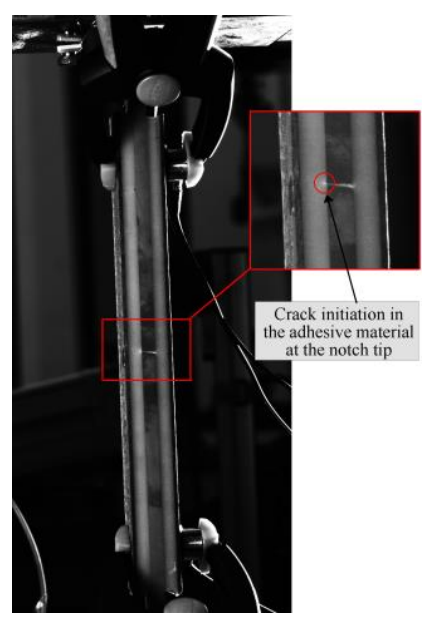

(b)

Figure 3. a) The load and AE frequency versus the displacement, and b) the camera image of Proset specimen since AE activities initiate.

The fractured specimens are shown in Figure 4. As expected, different damage mechanisms can be spotted for the two types of specimens. For the Scigrip specimens (see Figure 4(a)), the dominant damage mechanisms are plastic deformation and crack growth in the adhesive material. In addition, some steel/adhesive interfacial debondings can be spotted in the middle of the specimen, where the notch is, and at the upper and lower free edges. In addition, no delamination is observed in the CFRP skin for this type of specimens. Finally, there is infinitesimal debonding at the CFRP/adhesive interface at the middle of the specimen where the crack in the adhesive material reaches the CFRP/adhesive interface. In the case of Proset specimens (see Figure 4(b)), there is a complete debonding at the steel/adhesive interface and also a large interlaminar delamination in the CFRP skin. Moreover, some clear transverse cracks are seen in the adhesive.

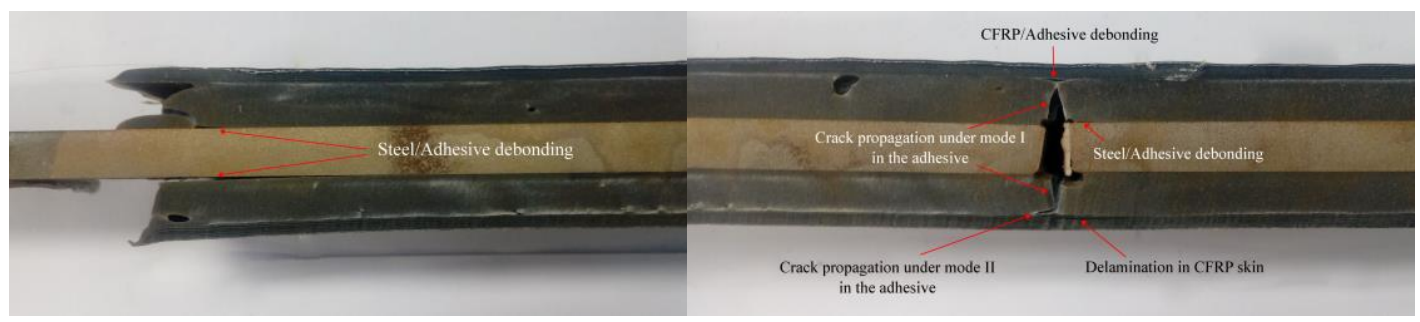

(a)

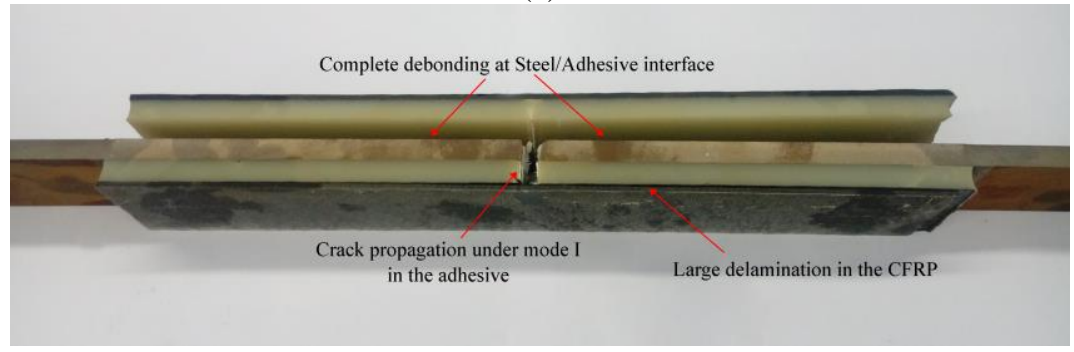

(b)

Figure 4. Different damage mechanisms in the fractured specimens a) Scigrip and b) Proset. 
In order to investigate the evolution behavior of each damage mechanism by AE, it is essential to first distinguish and classify the different damage mechanisms according to their AE features. To achieve this aim, standard tests on the individual constituents are conducted to simulate and capture the AE events associated with the damage mechanisms that occur in the double-lap joints. The specifications of the individual constituents tests are summarized in TABLE I.

The AE signals of the individual constituents' failure are collected from the aforementioned tests, and they are used to train an ensemble decision tree classifier. Thus, eight commonly used $\mathrm{AE}$ parameters consisting of amplitude, rise time, duration, counts, energy, RMS, centroid frequency, and peak frequency are extracted for each $\mathrm{AE}$ signal and fed into the classifier as the data features, and the signal label is defined as the response.

Cross-Validation method was used to protect the classification against overfitting by partitioning the data set into 5 folds and estimating the accuracy on each fold. The performance of the classifier is evaluated by the confusion matrix shown in Figure 5. The overall accuracy of the classification for Scigrip and Proset training data set is $99.5 \%$ and $99.8 \%$ respectively. This indicates that the classifier has been trained effectively and ensures its good performance to classify the DLJ specimen's signals. The largest error is associated with the "Steel deformation" in Scigrip specimen $(25 \%)$.

TABLE I. THE SPECIFICATIONS OF THE INDIVIDUAL CONSTITUENTS TESTS

\begin{tabular}{|cccc|}
\hline Material & Type of test & Standard & Data label \\
\hline Steel & Tensile & ASTM E8 [11] & Steel deformation \\
& Shear & ASTM B831 [12] & \\
Tensile & ASTM D638 [13] & \multirow{2}{*}{ Adhesive failure } \\
Adhesive & Mode I & Reference [14] & \\
& Mode II & Reference [14] & \\
Steel/Steel adhesively- & Mode I & ASTM D5528 [15] & \\
bonded DCB & & & Interfacial debonding \\
$\begin{array}{c}\text { CFRP/CFRP } \\
\text { adhesively-bonded }\end{array}$ & Mode I & ASTM D5528 [15] & \\
DCB & & & Skin failure \\
CFRP & Tensile & ASTM D3039 [16] & \\
\hline
\end{tabular}

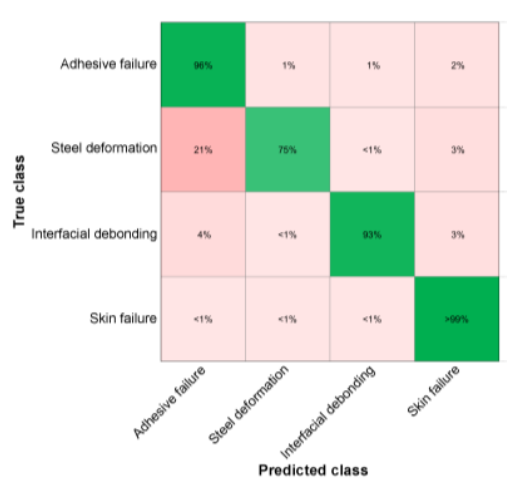

(a)
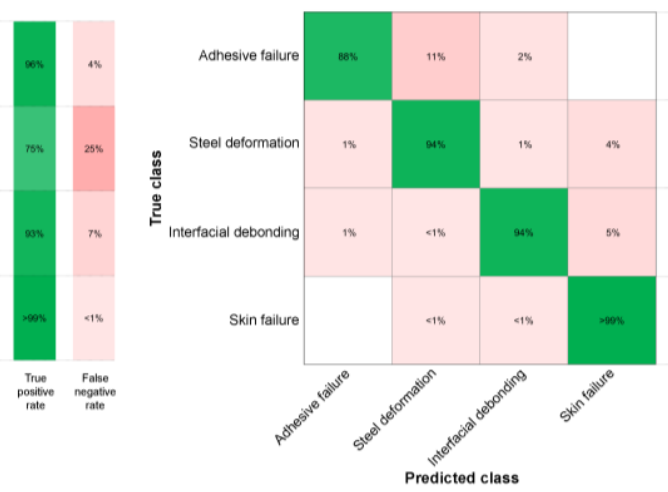

(b)

Figure 5. The confusion matrix of the trained model for training data set of specimens; a) Scigrip and b) Proset. 
After training the classifier, the AE signals of DLJ specimens are classified and labelled by the trained model. The cumulative AE energy curve of the four aforementioned damage mechanisms is shown in Figure 6. In the case of Scigrip specimen, damage is characterized by a progressive nature and it initiates at load levels which are much less than the maximum load. The AE accumulative curve (Figure 6(a)) suggests that the dominant damage mechanism is adhesive failure which is consistent with the visual inspection results (see Figure 4(a)). Interfacial debonding AE signals represents the second highest class of damage featuring the steel/adhesive interface debonding at the lower edges of the specimen as depicted in Figure 4(a). Although the AE accumulative curve suggests that there is skin failure in the Scigrip specimen, visual inspection (see Fig. 5(a)) does not show any visible delamination or fiber breakage in the CFRP skin. Thus, this can be due to matrix cracking occurring locally at the crack tip in the middle of the specimen's length. The measured longitudinal strain of the steel core at the maximum load was less than the yield strain. This ensures that the steel deformation's AE signals are due to the elastic deformation of steel and there is no concern about any yielding of the steel core.

Unlike the Scigrip specimen, the damage in the Proset specimen (see Figure 6(b)) occurs instantaneously at the maximum load. In this case, the dominant damage mechanisms captured by $\mathrm{AE}$ are skin failure and interfacial debonding. The stress singularity due to the crack tip in the case of the Proset adhesive leads to local fiber breakage and delamination initiating from the inner surface of CFRP skin (see Fig. 5(b)). This can be attributed to the brittle nature of the Proset adhesive as it does not undergo as much plastic deformation as the Scigrip counterpart. Again, the steel deformation signals are checked to ensure that they are due to the elastic deformation of the steel core with no sign of yielding.

\section{CONCLUSION}

Double-lap joint specimens were fabricated of a steel core bonded to two CFRP skins by two types of adhesive; a ductile "Scigrip" and a brittle "Proset". In-situ damage monitoring with $\mathrm{AE}$ during tensile loading of the joints revealed that the dominant damage in the Scigrip specimen was adhesive failure, while the interfacial debonding and the skin failure were the dominant damages of the Proset specimen.

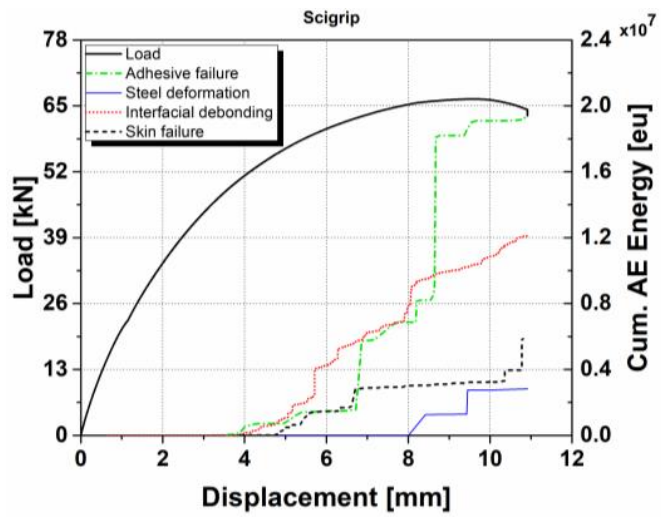

(a)

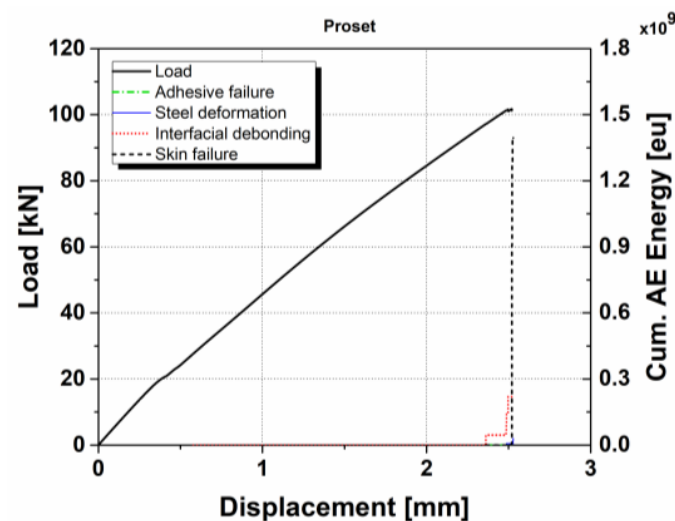

(b)

Figure 6. The cumulative AE energy curve of different damage mechanisms for a) Scigrip, and b) Proset DLJ specimens. 
In order to distinguish and classify different damage mechanisms by $\mathrm{AE}$, some standard tests were conducted on the individual constituents while the AE was recording the AE signals of individual damage mechanisms. These AE signals were used to train an ensemble bagged tree classifier. Then, the trained model classified the damage AE signals of Scigrip and Proset double-lap joint specimens. The dominant damage mechanisms predicted by $\mathrm{AE}$ were consistent with the visual inspection results. This study demonstrates the potential of AE technique for damage characterization of the adhesively-bonded bi-material joints.

\section{Acknowledgments}

This research was carried out within the project "QUALIFY-Enabling Qualifcation of Hybrid Joints for Lightweight and Safe Maritime Transport (2S03-051)", cofunded by the INTERREG 2Seas Mers Zeeen programme.

\section{REFERENCES}

[1] Sousa, J. M., J. R. Correia, J. P. Firmo, S. Cabral-Fonseca, and J. Gonilha. 2018. "Effects of thermal cycles on adhesively bonded joints between pultruded GFRP adherends," Compos. Struct., 202: pp. 518-529.

[2] Mariam, M., M. Afendi, M. S. Abdul Majid, M. J. M. Ridzuan, A. I. Azmi, and M. T. H. Sultan. 2019. "Influence of hydrothermal ageing on the mechanical properties of an adhesively bonded joint with different adherends," Compos. Part. B., 165: pp. 572-585.

[3] Yu, Q. Q., X. L. Gu, X. L. Zhao, D. Zhang, H. Huang, and C. Jiang. 2019. "Characterization of model uncertainty of adhesively bonded CFRP-to-steel joints," Compos. Struct., 215: pp. 150-165.

[4] Heshmati, M., R. Haghani, M. Al-Emrani, and A. André. 2018. "On the strength prediction of adhesively bonded FRP-steel joints using cohesive zone modelling," Theor. Appl. Fract. Mech., 93: pp. 64-78.

[5] Heshmati, M., R. Haghani, and M. Al-Emrani. 2017. "Durability of CFRP/steel joints under cyclic wet-dry and freeze-thaw conditions,” Compos. Part. B., 126: pp. 211-226.

[6] Lee, Y. H., D. W. Lim, J. H. Choi, J. H. Kweon, and M. K. Yoon. 2010. "Failure load evaluation and prediction of hybrid composite double-lap joints," Compos. Struct., 92: pp. 2916-2926.

[7] Fotouhi, M., M. Saeedifar, S. Sadeghi, M. Ahmadi Najafabadi, and G. Minak. 2015. "Investigation of the damage mechanisms for mode I delamination growth in foam core sandwich composites using acoustic emission," Struct. Health. Monit., 14(3): pp. 265-280.

[8] Xu, D., P. F. Liu, J. G. Li, and Z. P. Chen. 2019. "Damage mode identification of adhesive composite joints under hygrothermal environment using acoustic emission and machine learning," Compos. Struct., 211: pp. 351-363.

[9] ASTM D3528-96. 2016. "Standard test method for strength properties of double-lap shear adhesive joints by tension loading," West Conshohocken, PA, ASTM International.

[10] Breiman, L. 1996. "Bagging Predictors," Mach. Learn., 26: pp. 123-140.

[11] ASTM E8/E8M-16a. 2016. "Standard test methods for tension testing of metallic materials," West Conshohocken, PA, ASTM International.

[12] ASTM B831-14. 2014. "Standard test Method for shear testing of thin aluminum alloy products," West Conshohocken, PA, ASTM International.

[13] ASTM D638-14. 2014. "Standard test method for tensile properties of plastics," West Conshohocken, PA, ASTM International.

[14] Hasanpour, R. and N. Choupani. 2009. "Rock fracture characterization using the modified Arcan test specimen,” Int. J. Rock Mech. Min. Sci., 46(2): pp. 346-354.

[15] ASTM D5528-13. 2013. "Standard test method for mode I interlaminar fracture toughness of unidirectional fiber-reinforced polymer matrix composites," West Conshohocken, PA, ASTM International.

[16] ASTM D3039/D3039M-17. 2017. "Standard test method for tensile properties of polymer matrix composite materials," West Conshohocken, PA, ASTM International. 


\section{DEStech Publications, Inc.}

\section{CONTRIBUTING AUTHOR COPYRIGHT RELEASE FORM}

As author of the chapter/contribution titled "Structural Health Monitoring of Adhesively-Bonded Hybrid Joints by Acoustic Emission" to appear in the Proceedings of Structural Health Monitoring 2019, I hereby agree to the following:

1. To grant to DEStech Publications, Inc., 439 North Duke Street, Lancaster, PA, 17602, copyright of the above named chapter/contribution (for U.S.

Government employees to the extent transferable), in print, electronic, and online formats. However, the undersigned reserve the following:

a. All proprietary rights other than copyright, such as patent rights.

b. The right to use all or part of this article in future works.

DEStech Publications thereby retains full and exclusive right to publish, market, and sell this material in any and all editions, in the English language or otherwise.

1 I warrant to DEStech Publications, Inc., that I am the (an) author of the above-named chapter/contribution and that I am the (a) copyright holder of the above-named chapter/contribution granted to DEStech Publications, Inc.

2 I warrant that, where necessary and required, I have obtained written permission for the use of any and all copyrighted materials used in the abovenamed chapter/contribution. I understand that I am responsible for all costs of gaining written permission for use of copyrighted materials.

3 I agree to assume full liability to DEStech Publications, Inc. and its licensee, and to hold DEStech Publications, Inc. harmless for any claim or suit filed against DEStech Publications, Inc. for violation of copyrighted material used in the abovenamed contribution.

Please sign and date this form and retain a copy for your records. Please include original form with your chapter/paper.

Thank you for your cooperation.

Please print name: Milad Saeedifar

Signed:

Dated: 30-04-2019

439 NORTH DUKE STREET • LANCASTER, PENNSYLVANIA 17602-4967, U.S.A. Toll Free: (866) 401-4337 • Tel: (717) 290-1660 • Fax: (717) 509-6100 E-mail: info@destechpub.com • Internet address: www.destechpub.com 